\title{
Preface: Interdisciplinary contributions from the Division on Energy, Resources and the Environment at the EGU General Assembly 2019
}

\author{
Sonja Martens ${ }^{1}$, Christopher Juhlin ${ }^{2}$, Viktor J. Bruckman ${ }^{3}$, Gregor Giebel ${ }^{4}$, Thomas Nagel ${ }^{5}$, Antonio P. Rinaldi ${ }^{6}$, and \\ Michael Kühn ${ }^{1,7}$ \\ ${ }^{1}$ Fluid Systems Modelling, GFZ German Research Centre for Geosciences, Potsdam, 14473, Germany \\ ${ }^{2}$ Department of Earth Sciences, Geophysics, Uppsala University, Uppsala, 75236, Sweden \\ ${ }^{3}$ Institute of Forest Ecology (IFE), University of Natural Resources and Life Sciences, Vienna, 1190, Austria \\ ${ }^{4}$ Department of Wind Energy, Technical University of Denmark, Roskilde, 4000, Denmark \\ ${ }^{5}$ Geotechnical Institute, Technische Universität Bergakademie Freiberg, Freiberg, 09599, Germany \\ ${ }^{6}$ Swiss Seismological Service, ETH, Zürich, 8092, Switzerland \\ ${ }^{7}$ University of Potsdam, Institute of Geosciences, Potsdam, 14476, Germany
}

Correspondence: Sonja Martens (martens@gfz-potsdam.de)

Published: 21 August 2019

\begin{abstract}
Since 2004, the European Geosciences Union (EGU) brings together experts from all over the world at its annual General Assembly, covering all disciplines of the earth, planetary and space sciences. With this special issue in Advances in Geosciences, we are pleased to present a collection of contributions from the Division on Energy, Resources and the Environment (ERE) which were presented at the EGU General Assembly 2019 in Vienna.
\end{abstract}

\section{Introduction}

The EGU General Assembly 2019 was held from 7 to 12 April in Vienna, Austria. A total of 16273 scientists from 113 countries participated in the conference with 5531 oral, 9432 poster, and 1287 interactive presentations in 683 scientific sessions together with 87 short courses and 338 side events.

The ERE Division is one of 22 divisions organizing the EGU scientific activities and hosted 21 sessions with 411 presentations and co-organized another 20 sessions in 2019. Following our tradition, this volume of Advances in Geosciences contains scientific papers covering a large range of topics in the fields of energy, resources and the environment that were presented in the ERE sessions (EGU, 2019) and hereby continues a series of special issues from the previous years (Kühn et al., 2013, 2015, 2016; Juhlin et al., 2014; Martens et al., 2017, 2018).

\section{The ERE scientific program at the EGU General Assembly 2019}

As outlined in the United Nations' Sustainable Development Goal \#7 (UN, 2015), one major challenge for humankind is to provide affordable, reliable and clean energy supplies for all. These should be obtained in environmentally sustainable ways. Hence, the scientific program of the ERE division included the following subprograms during the General Assembly 2019 to provide a forum to the researchers to share their research findings and ideas, making use of synergies between the different disciplines involved:

- Integrated studies,

- Non-carbon based energy,

- Carbon based energy,

- Mineral resources,

- Geo-storage for a sustainable future, 
- Thermal-hydro-mechanical and/or chemical processes related to geoenergy applications,

- Geo-materials from natural resources.

\subsection{Integrated studies}

With the subprogram "Integrated studies", the ERE division was in the lead for the open session "Energy, Resources $\&$ the Environment" which gave an overview on interdisciplinary studies needed to tackle the challenges of the future. Among others, the presentations included an assessment of the UK's conventional oil and gas well sites remediation process (Clancy et al., 2019) and highlighted potentials for power-to-gas based subsurface energy storage in China (Ma et al., 2019a, b).

\subsection{Non-carbon based and renewable energy}

Renewable forms of energy, including wind and solar power, hydro and tidal power, geothermal energy, ambient heat captured by heat pumps, biofuels and the renewable part of waste, have developed in the European Union (EU) over recent years. While the share of energy from renewable sources accounted for $8.5 \%$ of gross final energy consumption in the EU in 2004, this share was $17.5 \%$ in 2017, on a path to the 2020 target of $20 \%$ (Eurostat, 2019).

The session "Energy Meteorology" focused on wind and solar power as the predominant new sources of electrical power in recent years. The success of wind power means that wind turbines are increasingly put in sites with complex terrain or forests and in offshore regions that are difficult to model and measure. For solar power, major challenges are accurate measurements and the short-term prediction of the spatiotemporal evolution of the effects of cloud field and aerosols. For both solar and wind power, the integration of large amounts of renewable energy into the grid is another research challenge due to the uncertainties linked to their forecast and to patterns of their spatiotemporal variabilities.

The session "Spatiotemporal modelling of distributed renewable energy systems" shared information on recent advances in geographic information systems (GIS)-based models extended by the temporal dimension. GIS are well established tools for the identification of potentials and the selection of optimal locations for installing renewable energy infrastructures. A number of studies present indicators of resource availability. These studies range from the determination of merely theoretical resources potentials to combined technical, economic, environmental and social studies of the suitability of energy generation technologies and they have reached high spatial detail. However, the consideration of the temporal variability of the energy demand and of highly fluctuating sources is a fundamental element that has been addressed only marginally in GIS-based approaches. The consideration of these fluctuations, however, is paramount to evaluating and designing spatially distributed energy systems with a high share of renewable sources.

Marine renewable energy includes offshore wind, wave, tidal range and tidal-stream energy. Understanding the environment these marine renewable energy devices are likely to operate in is essential when designing efficient and resilient devices. Furthermore, accurately characterising the resource and likely impacts is essential for the development of the marine renewable energy industry. The session "Marine renewable energy; resource characterisation, interactions and impacts" provided an insight on new research techniques and methods to better understand the interactions between energy extraction, the resource and the environment.

Biomass can support the aim to move towards a renewable energy and resource system, a so-called bio-economy. There is also a potential to realize net negative emissions, for instance with concepts, such as Bioenergy and Carbon Capture and Storage (BECCS). The session "Biomass in future energy and resource systems: impact on land use, climate and environmental services" comprised contributions assessing aspects of biomass production and utilization with implications on the environment at different scales.

With an increasing demand for low-carbon energy solutions, industrial development of geothermal resources is also accelerating. Current advancements target conventional hydrothermal systems as well as more unconventional systems. Optimum efficiency requires advanced understanding of the properties of the entire geothermal system, which needs to be combined with knowledge of heat sources, recharge areas and an integral understanding on how the different elements connect within one system. With the session "Conventional and unconventional geothermal resources: Advances in integrated approaches for exploration and monitoring" field, laboratory and numerical experts gathered to discuss this interdisciplinary environment.

The session "Numerical modelling in geothermics" offered the possibility to discuss advances and difficulties in all kinds of modelling geothermal processes. Models can originate from all phases of geothermal projects: prediction of geothermal potentials, optimization of borehole locations as well as the study of processes in existing geothermal installations. They can encompass all areas relevant for geothermics such as thermal, hydraulic, mechanical and chemical (THMC) processes.

\subsection{Carbon based energy}

The session "Gas hydrates in marine sediments: a potential resource and its influences on slope stability" focused on natural gas hydrates which are solid inclusion compounds composed of water and gas. They form as methane hydrates under elevated pressure and lower temperature conditions in marine sediments along continental margins. They bind large volumes of natural gas worldwide and may alter the strength of the upper sediment package along the margins based on 
their morphology, volume and the stability conditions. To date, neither the quantification of gas hydrate resources nor the impact of gas hydrates on sediment stability or slope failures are well constrained. This is despite their importance for the usage of the continental slope and its exploration, as well as exploitation of the unconventional hydrate reservoirs.

The session "Petroleum exploration and production and their impact on the environment" focused on advances in oil and gas exploration and production technologies as well as well as their associated environmental risks and economic benefits. The session "Unconventional hydrocarbon resources: Advances and new technologies" was devoted to advances in technologies and case studies relevant to the exploitation and exploration for unconventional hydrocarbon resources such as shale gas, tight sands and gas hydrates.

\subsection{Mineral resources}

The session "The New Roadmap for Mineral Exploration: Challenges and Innovative approaches" was organized as an inter- and transdisciplinary session (ITS). The aim of an ITS is to give a home to sessions that either link disciplines within the geosciences in a novel way to address specific and often new problems (interdisciplinary sessions) or that link the geosciences to other disciplines to address societal challenges (transdisciplinary sessions).

Most of the world-class ore discoveries have been made close to the surface. Many of these large-tonnage deposits are mined out or are largely decreasing in production. Mineral exploration at depth is becoming one of the fundamental challenges for the exploration industry in this century. The sharp increase in demand for commodities driven by a growing population and technology-based society is coupled with the decrease in world-class ore deposit discoveries in the last three decades. This is setting the stage for an unprecedented scenario that is ensuring that the market supply for critical metals is satisfied. This situation is becoming the driving force for a restructuring of mineral exploration paradigms. New technologies and methodologies are being developed; and, as a consequence, regions that were considered to be unfavourable for ore deposit exploration are now being reconsidered. This session comprised contributions on novel and innovative approaches to the search for mineral deposits for the future in new environments.

\subsection{Geo-storage for a sustainable future}

The session "Salt deposits as reservoir and storage space: research and development in subsurface and solution mining activities" shared information on the numerous aspects related to subsurface reservoir exploitation, solution mining, cavern operation and waste disposal in salt deposits. Within the last decades, not only the technology of salt production and the range of its uses have largely developed, also the technical options of experimental and field investigations have improved intensely. Depending on the application, the unique characteristics of salt deposits can be either an advantage or a challenge. For example, the high water solubility of salt rock offers the option to construct salt solution caverns, while the extremely low permeability allows for the temporary storage of various energy-rich fluids.

The session "Field studies on geological $\mathrm{CO}_{2}$ storage as a part of future energy systems" addressed aspects of $\mathrm{CO}_{2}$ storage at all scales, from laboratory and small field studies to full-scale storage projects. A number of pilot, demonstration and full-scale projects, have demonstrated the geological storage of $\mathrm{CO}_{2}$, as the last link in the Carbon Capture and Storage (CCS) chain over the past two decades. Natural analogues have provided additional evidence of the feasibility of long-term containment of carbon dioxide in geological formations.

A large merged session dealt with the topics "Assessment of barrier integrity in geological repositories for nuclear waste disposal and contaminant isolation" and "Towards a safe nuclear waste repository - geoscientific, technological, social and regulatory challenges and approaches". The successful implementation of safe, deep geological disposal of spent fuel, high-level waste and other long-lived radioactive waste is one of the currently most pressing and important environmental challenges in several countries in Europe and worldwide. Site exploration and assessment are primarily geoscientific tasks that require interdisciplinary collaboration of different geoscientific disciplines and geological as well as THMC modelling. Successful and socially accepted site selection and implementation, however, not only depend on geoscientific state-of-the-art results and research and development programs, but to a large extent on well-designed public outreach, public involvement/participation and on suitable regulatory frameworks.

Barrier integrity is a crucial aspect for the assessment of a wide range of subsurface technologies. For the storage of thermal energy and other energy carriers, or the deposition of high-level nuclear or chemotoxic waste, different repository concepts in diverse geological formations are being discussed. Computational methods and numerical simulations, in conjunction with experimental studies across scales are an integral part of safety and environmental-impact assessment concepts involving barrier integrity as a key component. This session provided a platform for the exchange of geophysical, geochemical, geotechnical knowledge for assessing barrier integrity and for contributions that highlighted the interdisciplinary and, especially, the transdisciplinary character of deep geological disposal research.

\subsection{Thermal-hydro-mechanical and/or chemical processes related to geoenergy applications}

Decarbonisation of the energy sector not only relies on subsurface storage, but also on maximizing the use of unconventional and renewable energy resources. However, many 
uncertainties exist regarding aspects such as the efficiency and potential of these resources and associated risks like induced seismicity. The session "Integrated lab, field and modelling studies in subsurface utilization" provided an overview of such aspects and focused on modelling of processes associated with geological subsurface utilization.

THMC processes in geological settings are of increasing interest in different geo-scientific fields. Hence, the session "Evaluation of coupled reservoir processes: from laboratory to field scale" provided a scientific platform to present and discuss studies focused on various kinds of processes relevant for geoenergy-related applications.

The presence of fractures, whether natural or induced, has become increasingly important in recent years in the exploitation of Earth's natural resources. Especially in rocks that have a low matrix permeability, the presence of fractures is critical for reaching flow rates sufficient for economic hydrocarbon production and heat extraction for geothermal reservoirs. Better prediction of subsurface fracture arrangements and their mechanical and flow response have become an increasingly relevant field of research. The session "Fracture, mechanics and flow in tight reservoirs" focused on the arrangement and mechanical evolution of fracture networks and their response to fluid flow in low-permeability rocks on a multitude of scales.

Numerous cases of induced/triggered seismicity have been reported in the last decades as a result of the increasing interest in fluid injection and extraction projects related to geo-resources exploration. When such seismicity is felt by the population, it can negatively affect public perception of geo-energies and may lead to the cancellation of important projects. Furthermore, large earthquakes may jeopardize wellbore stability and damage surface infrastructure. Thus, the session "Induced/triggered seismicity in geo-energy applications: monitoring, modelling, mitigation, and forecasting" was devoted to better understand how to monitor and model the processes leading to seismicity in order to facilitate the development of effective and reliable forecasting methodologies during deep underground exploitation.

Hydraulic stimulation is a well-operation that aims at enhancing fluid flow at depth. It is applied to exploit unconventional hydrocarbon reservoirs with low permeability and deep geothermal resources. Induced earthquakes frequently accompany the injection of fluids into boreholes potentially leading to damage to infrastructure at the surface and thus generally raising public concern. Hence, finding safe stimulation methods is critical for future use and public acceptance of geothermal energy projects and other potential forms of energy extraction from the underground. The session "Hydraulic testing, frac operations and induced seismicity in geoenergy projects" covered the full range of rock mechanics experiments, underground laboratory testing and field-scale operations aiming at improving the fundamental understanding of stimulation operations.

\subsection{Geo-materials from natural resources}

Construction materials, such as natural stone, aggregates, bricks, cement, lime and clay, form a wide and heterogeneous group characterized by their long-term use, importance for the society, and sensitivity to the environment. As our knowledge of many aspects of these materials is still rather limited the session "Geomaterials in construction: resources, properties, performance, environmental interactions, and decay" focused e.g. on the characterisation and optimization of traditional raw materials, as well as the monitoring and characterization of weathering features.

Natural stones are the main material used in architectonic heritage. The session "Heritage Stones: construction and restoration materials for sustainable development" dealt with those natural stone types that have achieved important use and significant recognition in human culture and emphasized the importance of Heritage Stones in the preservation of World Heritage sites.

\section{Conclusion}

The ERE division provided a manifold and comprehensive scientific program for the EGU's General Assembly 2019. Within this seventh ERE special issue since 2013, a collection of contributions is assembled with exciting results from research and development studies in the fields of energy, resources and the environment.

Acknowledgements. We would like to take this opportunity to thank all participants in the EGU General Assembly 2019, especially the conveners and presenters who made the ERE program possible. We would also like to extend our gratitude to all reviewers of the manuscripts submitted for consideration in this special issue for having so generously shared their expertise and time.

Financial support. The article processing charges for this openaccess publication were covered by a Research Centre of the Helmholtz Association.

\section{References}

Clancy, S., Worrall, F., Davies, R., and Gluyas, J.: An assessment of UK conventional oil and gas well sites remediation practices, Geophysical Research Abstracts, 21, EGU2019-1003, 2019.

EGU - European Geosciences Union General Assembly 2018: Selected program groups: ERE - Energy, Resources and the Environment, available at: https://meetingorganizer.copernicus.org/ egu2018/meetingprogramme, last access: 12 June 2019.

Eurostat: available at: https://ec.europa.eu/eurostat/ statistics-explained/index.php?title=Renewable_energy_ statistics/de\&oldid=206317, last access: 12 June 2019. 
Juhlin, C., Hangx, S., Ask, M., and Bruckman, V.: Energy, Resources \& the Environment: Current Status, Energy Proced., 59, 440-444, https://doi.org/10.1016/j.egypro.2014.10.400, 2014.

Kühn, M., Juhlin, C., Held, H., Bruckman, V., Tambach, T., and Kempka, T.: Energy, Resources \& the Environment - Some Future Challenges, Energy Proced., 40, 1-5, https://doi.org/10.1016/j.egypro.2013.08.001, 2013.

Kühn, M., Ask, M., Bruckman, V., Hangx, S., and Juhlin, C.: Sustainable Supply of Resources and Energy is a Challenge, Energy Proced., 76, 1-6, https://doi.org/10.1016/j.egypro.2015.07.833, 2015.

Kühn, M., Ask, M., Juhlin, C., Bruckman, V., Kempka, T., and Martens, S.: Interdisciplinarity to tackle the challenges of the future, Energy Proced., 97, 1-6, https://doi.org/10.1016/j.egypro.2016.10.004, 2016.

Ma, J., Li, Q., Kempka, T., and Kühn, M.: Hydromechanical Response and Impact of Gas Mixing Behavior in Subsurface $\mathrm{CH}_{4}$ Storage with $\mathrm{CO}_{2}$-Based Cushion Gas, Energ. Fuels, 33, 65276541, 2019a.
Ma, J., Li, Q., Nakaten, M., and Kühn, M.: Potentials for Powerto-Gas based subsurface energy storage in China, Geophysical Research Abstracts, 21, EGU2019-14691, 2019b.

Martens, S., Hangx, S., Juhlin, C., Kühn, M., and Kempka, T.: Energy, Resources and the Environment: Meeting the challenges of the future, Energy Proced., 125, 1-5, https://doi.org/10.1016/j.egypro.2017.08.301, 2017.

Martens, S., Juhlin, C., Bruckman, V. J., Mitchell, K., Griffiths, L., and Kühn, M.: Editorial: Energy, Resources and the Environment - Interdisciplinary answers to approach the sustainable energy and resources conundrum, Adv. Geosci., 45, 163-166, https://doi.org/10.5194/adgeo-45-163-2018, 2018.

UN - United Nations: Transforming our World: The 2030 Agenda for Sustainable Development, 2015. 